\title{
Rancang Bangun Aplikasi WebGIS untuk Pemetaan Kondisi Sosial Ekonomi Kota Batam
}

\author{
Ariyanto $^{1 *}$, Dwi Ely Kurniawan ${ }^{2 *}$, Agus Fatulloh ${ }^{3 * *}$ \\ * Teknik Informatika, Politeknik Negeri Batam \\ ** Teknik Multimedia Jaringan, Politeknik Negeri Batam \\ dwialikhs@polibatam.ac.id $^{2}$, agusf@polibatam.ac.id $^{3}$
}

\begin{tabular}{l}
\hline Article Info \\
\hline Article history: \\
Received 2018-04-01 \\
Revised 2018-06-21 \\
Accepted 2018-09-10 \\
\hline
\end{tabular}

Keyword:

Kondisi sosial,

Kepulauan Riau,

WebGIS.

\begin{abstract}
Kondisi sosial ekonomi suatu wilayah kepulauan merupakan suatu hal yang perlu disampaikan secara publik, mengingat ketererbatasan dan ketersedian kebutuhan dasar dari kehidupan dan kemampuan ekonomi masyarakat lokal. Penelitian ini mencoba untuk melakukan survey terkait kondisi sosial ekonomi Kepuluan Riau dengan teknik penggalian sumber data BPS dan survey lokasi. Hasil survey kemudian diolah dan divisualkan dalam bentuk WebGIS untuk memudahkan dalam menampilkan informasi spasial. Digitasi peta menggunakan QuantumGIS berupa titik, garis dan polygon. Layanan server map menggunakan ArcGIS Online. WebGIS dikembangkan menggunakan CSS Bootstrap dengan menggabungkan data peta sehingga peta dapat mudah diakses dan menampilkan informasi dari berbagai perangkat dan platform. Harapannya memudahkan pihak CSR atau pemerintah dalam membuat keputusan terhadap kondisi sosial masyarakat.
\end{abstract}

Copyright (C) 2018 Journal of Applied Informatics and Computing. All rights reserved.

\section{Pendahuluan}

Kota Batam merupakan salah satu kota terbesar yang ada di Kepulauan Riau. Setiap tahunnya laju pertumbuhan penduduk di Kota Batam selalu mengalami peningkatan. Peningkatan laju pertumbuhan penduduk di Kota Batam disebabkan banyaknya penduduk dari luar yang datang ke Kota Batam untuk mencari pekerjaan. Berdasarkan data statistik daerah Kota Batam, jumlah penduduk pada tahun 2014 mengalami peningkatan di tahun 2015 sebanyak 6.659 jiwa yaitu dari 1.030 .528 jiwa menjadi 1.037 .187 jiwa. Peningkatan jumlah penduduk ini dapat menyebabkan berbagai permasalahan sosial seperti meningkatnya jumlah pengangguran, rumah liar, anak jalanan yang akan berdampak terhadap kondisi sosial ekonomi masyarakat Kota Batam.

Kondisi sosial ekonomi merupakan suatu kedudukan yang diatur secara sosial dan menempatkan seseorang pada posisi tertentu dalam masyarakat. Kondisi sosial ekonomi masyarakat dapat dilihat melalui tiga aspek antara lain pendidikan, pekerjaan dan pendapatan. Pendidikan berperan penting dalam upaya menciptakan manusia yang berkualitas. Semakin tingggi tingkat pendidikan seseorang maka akan mempermudah untuk mendapatkan pekerjaan dengan pendapatan tinggi, begitupun sebaliknya semakin rendah tingkat pendidikan seseorang maka untuk mencari pekerjaan pun akan sulit yang akan berdampak terhadap kondisi sosial ekonominya.

Kondisi sosial ekonomi masyarakat dapat dikatakan baik apabila telah terpenuhi kebutuhan sehari-harinya baik itu kebututuhan sandang, pangan maupun papan, sebaliknya apabila salah satu dari kebutuhan itu tidak terpenuhi maka dapat dikatakan bahwa kondisi sosial ekonominya itu buruk.

Di Kota Batam sendiri permasalahan sosial tersebar di berbagai kecamatan. Untuk mengatasi hal tersebut perbaikan kondisi ekonomi masyarakat merupakan hal yang paling penting untuk dilakukan. Dalam hal ini perlu diketahui kondisi sosial ekonomi masyarakat di setiap kecamatan sehingga akan memudahkan dalam mengambil sebuah keputusan baik itu pihak pemerintah, swasta dan lain sebagainya.

Salah satu cara yang bisa dilakukan yaitu dengan melakukan clustering. Clustering merupakan metode data mining yang digunakan untuk mengelompokkan objek yang memiliki tingkat kemiripan yang tinggi dalam satu cluster, dimana setiap cluster memiliki tingkat perbedaan yang tinggi dengan cluster lainnya. Algoritma clustering yang akan dipakai yaitu K-Means clustering.

Clustering kemudian digunakan untuk pengelompokan di masing-masing kecamatan. Dari hasil clustering dapat dilihat karakteristik dari masing-masing kecamatan sehingga dapat 
diidentifikasi kondisi sosial ekonominya. Selanjutnya informasi yang didapatkan akan diolah menggunakan GIS.

\section{LANDASAN TEORI}

\section{A. Kondisi Sosial Ekonomi}

Kondisi sosial ekonomi adalah keadaaan atau kedudukan yang diatur secara sosial yang menempatkan seseorang dalam posisi tertentu dalam masyarakat, pemberian posisi itu disertai pula dengan seperangkat hak dan kewajiban yang harus dimainkan oleh orang yang membawa status tersebut. Kondisi sosial ekonomi dipengaruhi oleh beberapa faktor yaitu faktor ekonomi, faktor budaya, faktor, faktor pendidikan, faktor kependudukan, dan faktor kesehatan.

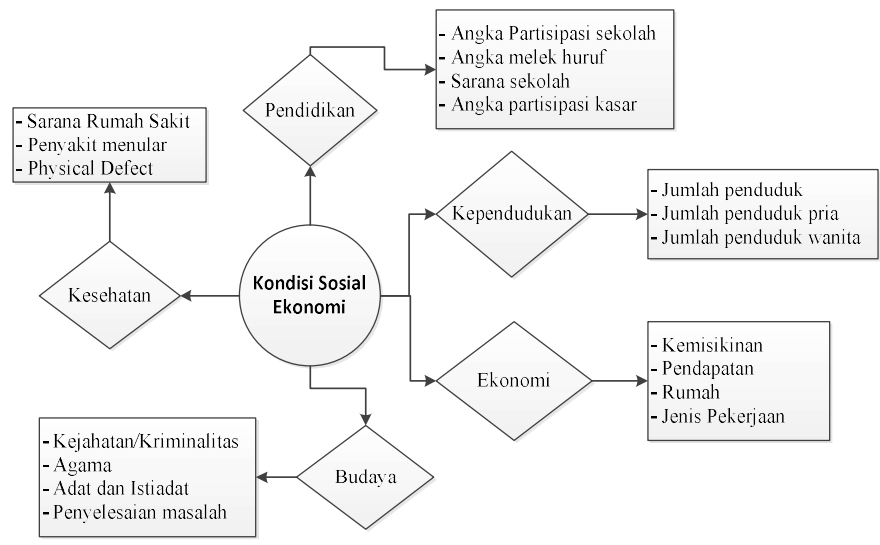

Gambar 1. Mind Mapping Kondisi Sosial Ekonomi

\section{B. QuantumGIS}

Quantum GIS (QGIS) adalah cross-platform perangkat lunak bebas (open source) desktop pada Sistem Informasi Geografis (SIG). Aplikasi ini memiliki fungsi yaitu menyediakan data, melihat, mengedit, dan memiliki kemampuan analisis spasial. QGIS ditulis dalam bahasa pemrograman $\mathrm{C}++$. Data yang diolah pada QGIS dapat berupa data raster maupun vector. QGIS dapat mengolah hamrpir semua format data spasial diantaranya shapefile, coverage data, dan lain-lainnya. Kelebihan Quantum GIS (QGIS):

- Dapat membuka banyak jenis data spasial.

- Tampilan QGIS simpel dan user-friendly.

- Lisensi dan open source.

- Remote sensing processiong tool yang lebih baik.

- GeoCoding dan alat data konversi di QGIS gratis.

\section{ArcGIS Online}

ArcGIS online merupakan kolaboratif web GIS berbasis cloud yang memungkinkan untuk membuat, berbagi peta, scenes, aplikasi, layers, analisis dan data. Arc GIS online merupakan bagian integral dari ArcGIS system sehingga dapat digunakan untuk memperluas kemampuan ArcGis baik untuk Desktop, ArcGIS untuk sever, API Web, dan ArcGIS Runtime SDK.

\section{Analisa dan Perancangan}

Analisa perancangan meliputi use case diagram, scenario, activity diagram, sequence diagram dan class diagram.

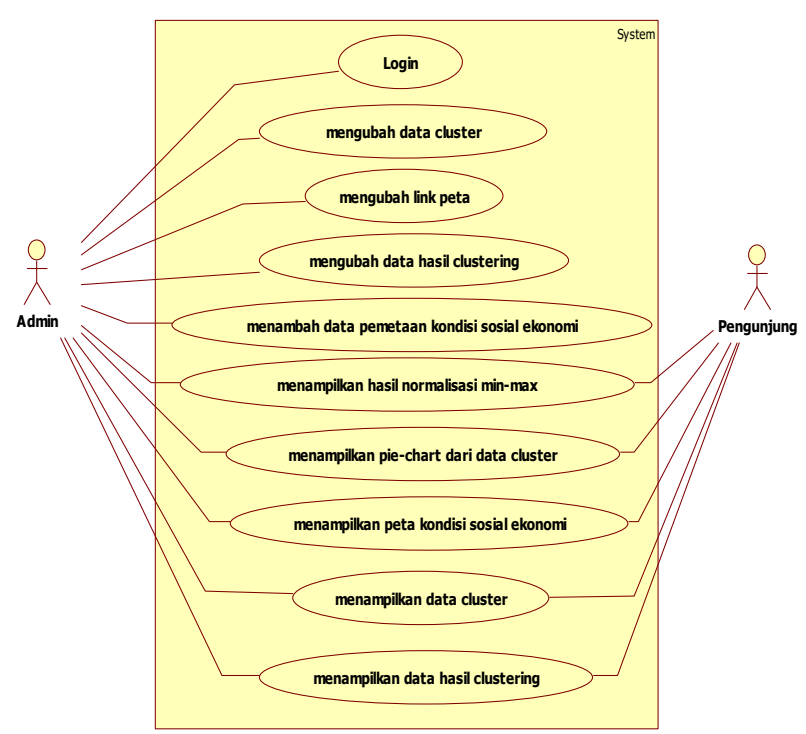

Gambar 2. Use case diagram aplikasi webGIS

Gambar 2 menjelaskan bahwa admin memiliki hak akses ke sistem yaitu login, mengubah data cluster, mengubah link peta, mengubah data hasil clustering, menampilkan hasil normalisasi min-max, menampilkan pie-chart dari data cluster, menampilkan peta kondisi sosial ekonomi, menampilkan data cluster, dan menampilkan data hasil clustering. Sementara pengunjung memiliki hak akses ke sistem yaitu menampilkan hasil normalisasi min-max, menampilkan pie-chart dari data cluster, menampilkan peta kondisi sosial ekonomi, menampilkan data cluster, dan menampilkan data hasil clustering.

TABEL I

Skenario Menambah Data PemetaAn Kondisi Sosial EkonomI

\begin{tabular}{|c|c|}
\hline $\begin{array}{l}\text { Nama Use } \\
\text { Case }\end{array}$ & $\begin{array}{l}\text { Menambah data pemetaan kondisi sosial } \\
\text { ekonomi }\end{array}$ \\
\hline Aktor & Admin \\
\hline Kondisi Awal & Admin telah masuk ke aplikasi \\
\hline Kondisi Akhir & $\begin{array}{l}\text { Admin berhasil menambah data pemetaaan } \\
\text { kondisi sosial ekonomi }\end{array}$ \\
\hline Skenario & $\begin{array}{ll}\text { 1. } & \text { Admin memilih file excel yang akan } \\
\text { digunakan } \\
\text { 2. Admin memasukkan data tahun } \\
\text { 3. Admin memasukkan link peta } \\
\text { 4. Sistem melakukan validasi dari file yang } \\
\text { dimasukkan } \\
\text { 5. } \\
\text { Sistem menyimpan data ke database } \\
\end{array}$ \\
\hline $\begin{array}{l}\text { Skenario } \\
\text { Alternatif }\end{array}$ & $\begin{array}{l}\text { 2a[file yang dimasukkan salah] kembali ke } \\
\text { langkah } 1\end{array}$ \\
\hline
\end{tabular}




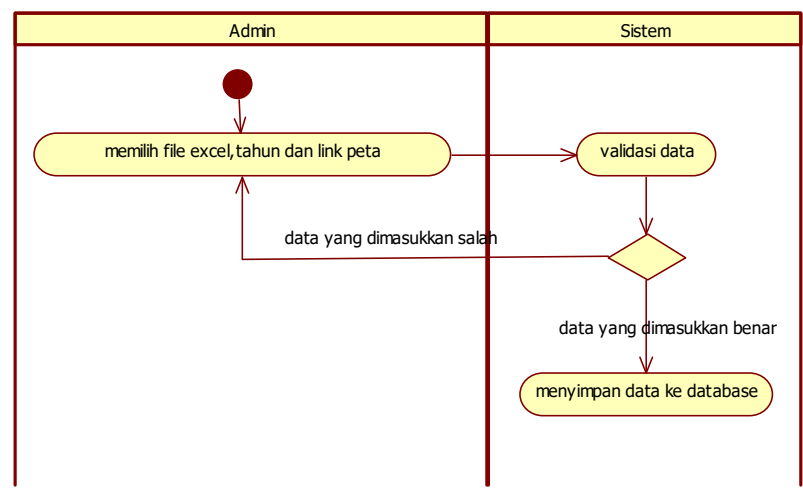

Gambar 3. Activity diagram menambah data pemetaan kondisi sosial ekonomi

Gambar 3 menjelaskan proses untuk menambah data pemetaan kondisi sosial ekonomi yaitu admin memilih file yang akan dimasukkan, memasukkan tahun dan link peta kemudian sistem akan melakukan verifikasi data lalu menyimpannya ke database.

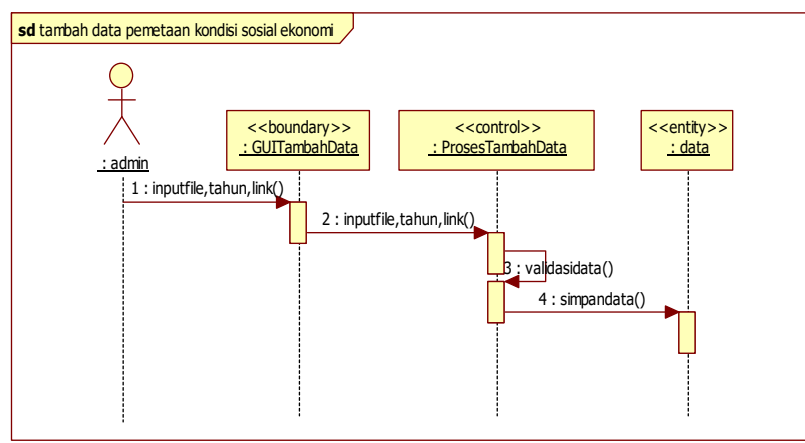

Gambar 4. Sequence diagram menambah data pemetaan kondisi sosial ekonomi

Sequence diagram menambah data pemetaan kondisi sosial ekonomi yaitu admin memilih file yang akan dimasukkan, memasukkan tahun dan link perta kemudian sistem akan melakukan validasi data terlebih dahulu lalu menyimpannya ke database.

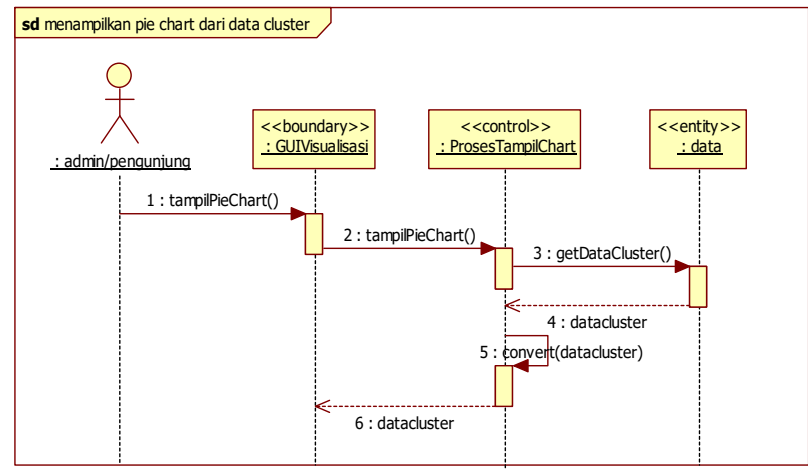

Gambar 5. Sequence diagram menampilkan pie-chart
Sequence diagram menampilkan pie-chart dari data cluster, merupakan sequence diagram menampilkan pie-chart dari data cluster yaitu ketika admin/pengunjung membuka halaman visualisasi sistem akan menampilkan pie-chart dari data cluster.

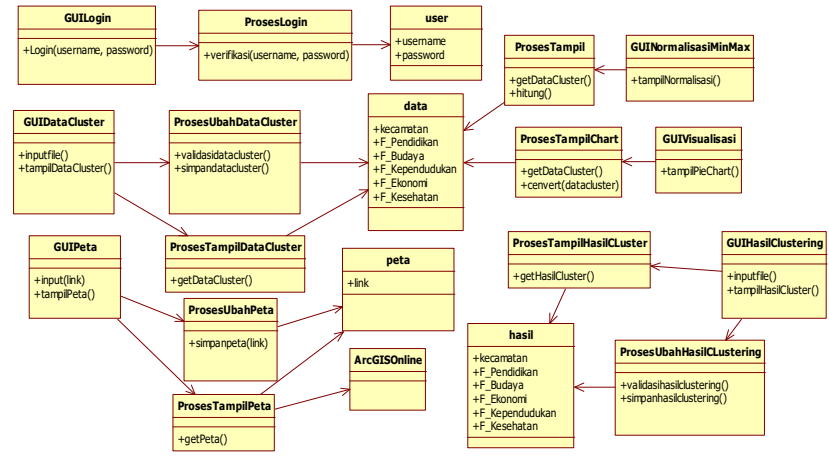

Gambar 6. Class Diagram

Gambar 6 menunjukkan class diagram dimana, class GUILogin memiliki hubungan class proseslogin dan class user. Class GUIDataCluster memiliki hubungan dengan class ProsesUbahDataCluster, class ProsesTampilDataCluster dan class data. Class GUIPeta memiliki hubungan dengan class ProsesUbahData, class ProsesTampilPeta, class ArcGISOnline dan class peta. Class GUINormalisasiMinMax memiliki hubungan dengan class ProsesTampil dan class data. Class GUIVisualisasi memiliki hubungan dengan class ProsesTampilChart dan class data. Class GUIHasilClustering memiliki hubungan dengan class ProsesUbahHasilClustering, class ProsesTampilHasilCluster dan class hasil.

Setelah melakukan analisa perancangan aplikasi webGIS selanjutnya adalah melakukan digitasi dari peta Kota Batam menggunakan QuantumGIS.

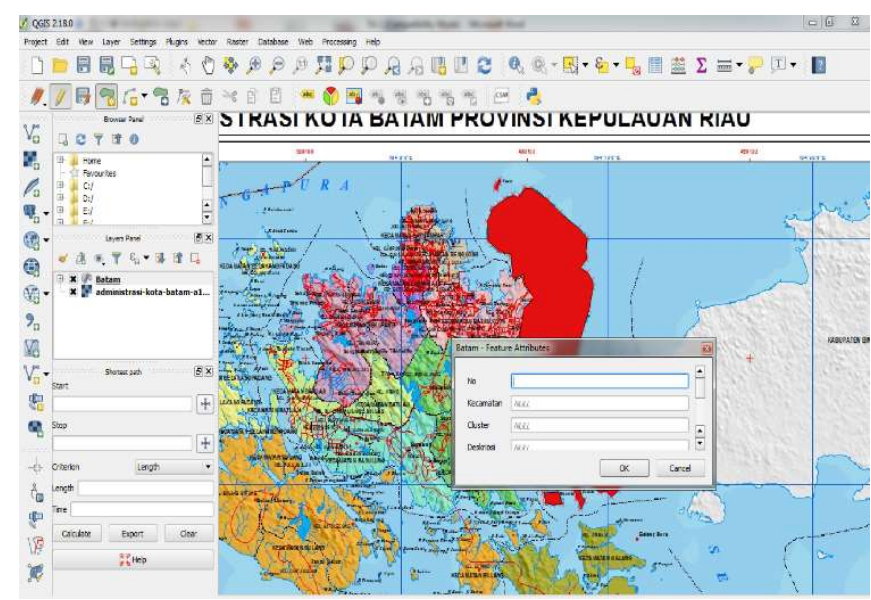

Gambar 6. Digitasi menggunakan QuantumGIS

Data statistik yang diperoleh dari hasil survey dan penggalian sumber data BPS maka digabungkan dengan data spasial dengan menggunakan Quantum GIS. Setelah itu 
melayout peta dengan menggunakan ArcGIS Online dengan mengimport data hasil dari digitasi Quantum GIS tersebut. Kemudian melakukan embedded sourcode ke dalam website yang dibuat.

\section{HASIL DAN IMPLEMENTASI}

Hasil implementasi dari perancangan aplikasi webGIS disajikan pada gambar berikut.

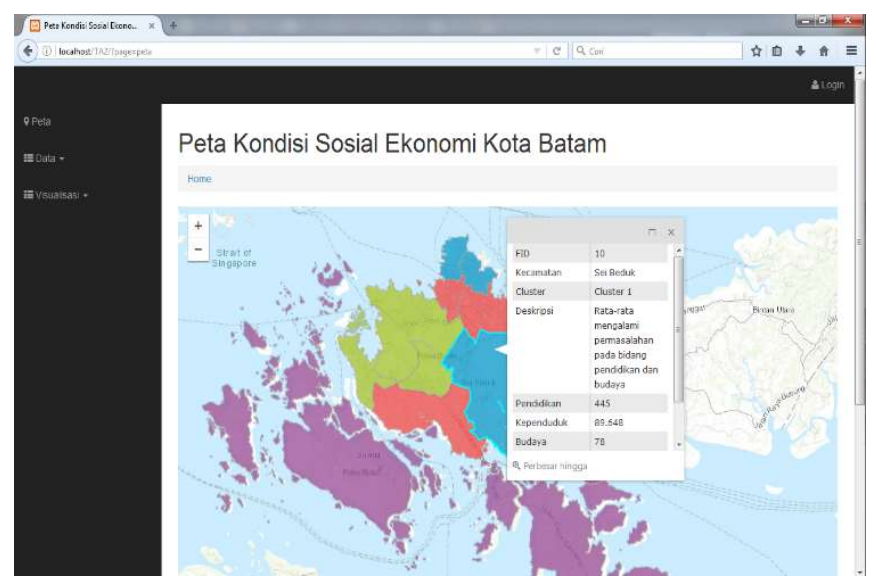

Gambar 7. Hasil implementasi webGIS

Gambar 7 menunjukkan implementasi antarmuka peta yang menampilkan peta kondisi sosial ekonomi yang berisi tentang informasi kondisi sosial ekonomi Kota Batam yang didapatkan dari data yang telah dilakukan proses clustering.

Agar memudahkan pengguna dalam mengetahui data sosial setiap kecamatan ditampilkan dalam bentuk gambar pie-chart. Harapannya agar memudahakan pihak-pihak CSR atau pemerintah dalam membuat keputusan terhadap kondisi sosial masyarakat.

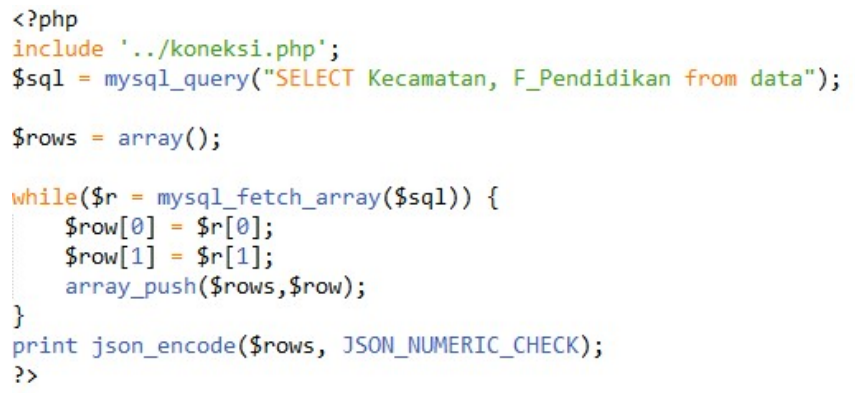

Ketika pengguna membuka halaman menu visualisasi, sistem akan mengambil data cluster dari database kemudian menampilkannya dalam bentuk pie-chart.

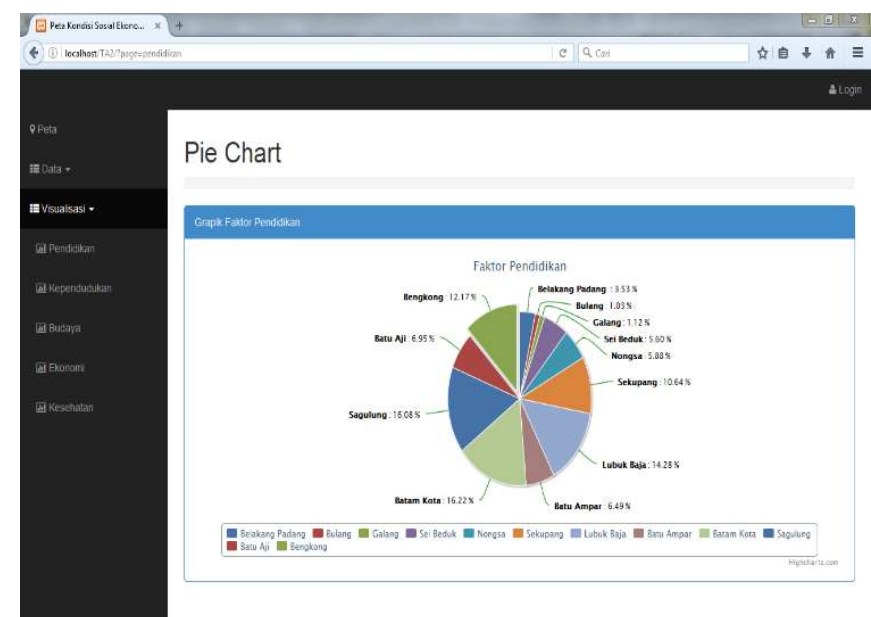

Gambar 8. Pie-chart data kondisi sosial dalam webGIS

Selain itu setiap area dalam kecamatan menampilkan berbagai warna contohnya hijau, merah, ungu, biru dll. Area polygon ini dapat di klik dan memunculkan informasi terkait kondisi sosial ekonomi masyarkat Kota Batam.

\section{KESIMPULAN}

Aplikasi webGIS telah dikembangkan dengan menggunakan QuantumGIS, ArcGIS Online dan CSS Bootstrap. Aplikasi mampu menampilkan secara visual GIS dalam menampilkan data kondisi social ekonomi masyarakat Kota Batam berupa kepdatan penduduk, ekonomi, pendidikan, kesehatan dan budaya. Harapannya memudahkan pihak CSR atau pemerintah dalam membuat keputusan terhadap kondisi sosial masyarakat.

\section{UCAPAN TERIMA KASIH}

Penulis mengucapkan terima kasih kepada Ristek Dikti dan P3M Politeknik Negeri Batam dalam hibah penelitian ini.

\section{DAFTAR PUSTAKA}

[1] Arief, M.R., 2011, Pemrograman Web Dinamis Menggunakan Php dan Mysql, Yogyakarta, ANDI.

[2] Asroni, Ronald, A., 2015, Penerapan Metode K-Means Untuk Clustering Mahasiswa Berdasarkan Nilai Akademik Dengan Weka Interface Studi Kasus Pada Jurusan Teknik Informatika UMM Magelang, Jurnal Ilmiah Semesta Teknika 18(1), 76-82.

[3] Edvira, R., 2010, Aplikasi K-Means Cluster Untuk Pengelompokan Provinsi Berdasarkan Produksi Padi, Jagung, Kedelai, Dan Kacang Hijau Tahun 2009, Jurnal Mat Stat 10(2), 122-134.

[4] Jiawei, H. Micheline, K., 2006, Data Mining: Concepts and Techniques, San Fransisco, Morgan Kaufmann Publishers.

[5] Kurnia, M. Anie R.I. Anggun, F., 2013, Perancangan WEB-GIS Penyebaran Wabah Penyakit Demam Berdarah Dengue (DBD) dan Malaria di Kota Bandar Lampung, Jurnal Komputasi 1(1).

[6] Z. Agha, A. Triwinarko, and B. Hamuna, "Pemetaan Industri di Kota Batam Menggunakan Mobile GIS Berbasis Android”, JAIC, vol. 1, no. 1, pp. 1-4, Jul. 2017.

[7] Kurniawan, D. E., \& Fatulloh, A. (2018). Clustering of Social Conditions in Batam, Indonesia Using K-Means Algorithm and Geographic Information System.

[8] Rastuti, Leon, A.A, Eka, P.A., 2015, Sistem Informasi Geografis Potensi Wilayah Kabupaten Banyuasin Berbasis Web, Student Colloquium Sistem Informasi \& Teknik Informatika (SC-SITI). 